\title{
ANTES DE VOTAR DEBEREMOS CONOCER ALGUNOS DETALLES IMPORTANTES
}

\section{BEFORE VOTING WE SHOULD KNOW SOME IMPORTANT DETAILS}

Joaquín González López: AJURA: Asociación de apoyo al Jurado Público ajura-ong@terra.es

\section{CURRICULUM VITAE}

Licenciado y Doctor en historia del arte y en historia y ciencias de la música por la Universidad de Granada (España). Profesor y Director de la Cátedra Manuel de Falla (Granada, España)

\section{RESUMEN}

Hace poco más de 25 años los españoles votamos en referéndum para aprobar la Constitución Española. Ésta garantizaba una serie de derechos cívicos que incluso muchos desconocíamos por no habérsenos informado de los acuerdos adoptados que se relacionan en la Declaración Universal de los derechos humanos. Por eso este artículo viene a decir que aquello, por lo que se expone en determinados artículos, fue una tomadura de pelo. 


\section{PALABRAS CLAVE}

Constitución Española - Derechos cívicos - Artículos - Ley

\section{ABSTRACT}

Just over 25 years the Spanish referendum voted to approve the Spanish Constitution. This guaranteed a series of civil rights that even many unaware not informed of the decisions taken relating to the Universal Declaration of Human Rights. So this article is to say that, as stated in certain articles, it was a joke.

\section{KEY WORDS}

Spanish Constitution - Civil Rights - Articles - Law

TEXTO:

AJURA INFORMA: Hace ahora poco más de 25 años que la mayoría de los españoles, de uno y otro bando de las divididas Españas, con gran ilusión votamos en referéndum aprobando la constitución Española hoy vigente cuya principal misión era la unificación de las Españas. Estábamos tan ilusionados con lo consensuado -la mayor parte de los ciudadanos- que no podíamos sospechar que fueran los máximos representantes de la Soberanía Popular los que nos tomaran el pelo como ahora nos lo están tomando según podremos comprobar con lo expuesto en este Manifiesto. 
Con ilusión, antes de votar, pudimos observar que aquella Carta Magna garantizaba una serie de derechos cívicos que incluso muchos desconocíamos por no habérsenos informado de los acuerdos adoptados que se relacionan en la Declaración Universal de los derechos humanos.

Con gran alegría pudimos observar como la Constitución, en su art. 1, dispone que España se constituye en Estado social y democrático de Derecho, que propugna como valores superiores de su ordenamiento jurídico la libertad, la justicia, la igualdad y el pluralismo político. Que la soberanía nacional reside en el pueblo español, del que emanan los poderes del Estado.

En su art. $9^{\circ}$ dispone: Los ciudadanos y los poderes públicos están sujetos a la Constitución y al resto del ordenamiento jurídico. 9.3: La Constitución garantiza el principio de legalidad, la jerarquía normativa, la publicidad de las normas, la seguridad jurídica, la responsabilidad la interdicción de la arbitrariedad de los poderes públicos.

En cuanto a Los derechos y deberes fundamentales dispone: La dignidad de la persona, los derechos inviolables que le son inherentes, el libre desarrollo de la personalidad, el respeto a la ley y a los derechos de los demás son fundamento del orden político y de la paz social. Las normas relativas a los derechos fundamentales y a las libertades que la Constitución reconoce se interpretarán de conformidad con la declaración Universal de los Derechos Humanos y los tratados y acuerdos internacionales de las mismas materias ratificados por España.

A continuación la Constitución nos garantiza el derecho de igualdad de trato ante la ley. Del derecho a la vida. A la libertad y a la seguridad. Dispone que toda persona detenida debe ser informada de forma inmediata de sus constitucionales derechos cívicos. Se garantiza el derecho al honor, a la intimidad personal y familiar y a la propia imagen. Nos garantiza la inviolabilidad del domicilio. El secreto de las 
comunicaciones. Nuevamente el honor. A expresar y difundir libremente los pensamientos, ideas y opiniones mediante la palabra, el escrito o cualquier otro medio de reproducción.

Dispone entre otros: Los ciudadanos tienen derecho a participar en los asuntos públicos, directamente o por medio de sus representantes, libremente elegidos en elecciones periódicas por sufragio universal. Tiene derecho a obtener la tutela efectiva de los jueces y tribunales en el ejercicio de sus derechos e intereses legítimos, sin que, en ningún caso, pueda producirse indefensión. Al juez ordinario predeterminado por la ley. A la presunción de inocencia, a la defensa y a la asistencia de letrado

A un proceso público sin dilaciones indebidas y con todas las garantías. Se reconocen los derechos de asociación y el de sindicarse libremente. También se reconoce el derecho a la huelga. Y el derecho de petición del que luego hablaremos más ampliamente.

\section{LA TOMADURA DE PELO SE RAZONA:}

Dispone El constitucional artículo 53.2: Cualquier ciudadano podrá recabar la tutela de las libertades y derechos cívicos ante los tribunales ordinarios por un procedimiento basado en los principios de preferencia y sumariedad y, en su caso, a través del recurso de amparo ante el Tribunal Constitucional.

Comienza lo que algunos llamarían estafa otros cachondeo lo que también pudiera denominarse tomadura de pelo: La Ley 62/1978, de protección jurisdiccional de los Derechos Fundamentales de la Persona, que desarrolla lo dispuesto en el constitucional artículo anteriormente citado, en su artículo $1.1^{\circ}$ dispone: Los delitos y faltas contra los derechos fundamentales de la persona, comprendidos en el ámbito de aplicación de esta ley serán enjuiciados por los juzgados y tribunales de la 
jurisdicción ordinaria, según su propia competencia. Y, en el apartado siguiente (2.2) dispone: Para el enjuiciamiento de estos delitos y faltas se observarán las normas del procedimiento de la Ley de Enjuiciamiento Criminal.

\section{AHÍ QUERÍAMOS LLEGAR:}

La mayoría de los españoles desconocen que la Ley de Enjuiciamiento Criminal, a la que cita la Ley 62/1978, se aprobó el 14 de septiembre de 1882, en una época en la que los derechos cívicos no eran ni tan siquiera conocidos por lo que no sirve de nada recurrir a un texto legal inoperante que desconoce los derechos que debe defender o los delitos que debe castigar puesto que no conoce de ningún tipo de derecho cívico. Tenga el lector una clara idea de la antigüedad o diferencia existente entre aquella España de 1882 y esta España democrática del Siglo XXI donde los poderes absolutistas han pasado a la historia pero el Poder Oligárquico continúa sin reconocer los fundamentales derechos del administrado.

En aquellas fechas la corrupción político-judicial era de tal envergadura que propició el que el pueblo soberano decidiera abandonar el Poder Absolutista de Don Alfonso XIII y eligiera la República como forma idónea de Gobierno, donde la justicia funcionara mejor y los ciudadanos gozaran de algunos derechos cívicos.

Esa Ley de Enjuiciamiento Criminal, que pudo ser de gran utilidad para el Poder Oligárquico en épocas restrictivas de las libertades cívicas, sólo sirve sino para que jueces y tribunales supuestamente corruptos puedan, si así lo desean, administrar parcial justicia. Tal es el caso de la querella criminal presentada por la Asociación Libre de Abogados contra el actual Presidente del Gobierno Don José Maria Aznar López, presentada por haber vulnerado el querellado la Constitución Española vigente en el tema de Iraq. 
Esa querella criminal continúa sin ser aceptada por la Sala, pero ya el Ministerio Fiscal, ha informado a la Sala que procede acogerse a lo dispuesto en el artículo 313 de la Ley de Enjuiciamiento criminal. Estos documentos prueban que aquella Ley de Enjuiciamiento Criminal no se actualiza por cuanto permite al juzgador prejuzgar y resolver sin necesidad de escuchar a las partes como disponen tanto la Declaración Universal de los Derechos Humanos, como la Constitución Española hoy vigente y nos corresponde a todos por todo el dinero que aportamos al sostenimiento de los gastos públicos.

Sirva este otro ejemplo del alto índice de corrupción político-judicial alcanzado en España después de 25 años de haberse consensuado la Constitución como Ley Fundamental para acabar con la división de las Españas. De espaldas a lo dispuesto en la Ley Orgánica 1/2002 reguladora del derecho de petición, sea precisamente la Comisión de Peticiones del Congreso de los Diputados que preside un miembro del Grupo Parlamentario Popular, la que intencionadamente vulnere el constitucional derecho de petición de la asociación AJURA; la Asociación Libre de Abogados; la Asociación para la Defensa del Estado de Derecho; y, la Coordinadora de Ciudadanos Agobiados y Cabreados impidiendo que tal consulta llegue a conocimiento de la Comisión de Justicia del Congreso de los Diputados ante la que se ejerció tal derecho.

La consulta textualmente decía: Quienes firman este escrito exponen a los miembros del Congreso de los Diputados sobre dos claros ejemplos de que los textos legales citados se están transgrediendo: El primero cuando la Sala Segunda del Tribunal Supremo tratando de arrebatar de la acción de la Justicia a un Magistrado-Juez ya juzgado y condenado por haber prevaricado, según sentencia dictada por el Tribunal Superior de Justicia de Madrid que devino en firme el 19 de mayo de 1993, en un claro ejercicio corporativo en contra de lo dispuesto en los artículos 12.2 y 18.1 de la Ley Orgánica del Poder Judicial, sin haber sido presentado recurso alguno, el 13 de 
julio de 1993 -mediante extenso Auto de 16 páginas- la citada Sala Segunda del Tribunal Supremo, dijo: El artículo 313 de la Ley Procesal Penal ordena desestimar la querella cuando los hechos en que se funde no constituyan delito, lo que sucede en este caso; y/o cuando la Sala Especial del Tribunal Supremo trato de resolver la querella presentada por los supuestos delitos de prevaricación en que pudieran haber incurrido aquellos que resolvieron de forma tan sorprendente como contraria al ordenamiento jurídico, dicto un Auto -de 32 páginas fechado el 14 de julio de 1999- que terminaba diciendo: OCTAVO: En consecuencia, pues, es totalmente erróneo e inadmisible tachar de injustos a los Autos del Tribunal Supremo de 13 de julio y 13 de octubre de 1993. Por ende, dado lo que establece el artículo 313 de la ley de Enjuiciamiento Criminal, procede desestimar la querella presentada ante esta Sala Especial del art. 61 de la LOPJ el 18 de diciembre de 19998, en nombre y representación de don Joaquín González López.

La consulta realizada ante la Comisión de Justicia del Congreso de los diputados, textualmente preguntaba: ¿Cuándo los hechos denunciados, ante los tribunales ordinarios, son constitutivos de delito según lo previsto en el Código Penal -como es el delito de prevaricación por ejemplo- las resoluciones judiciales de sobreseimiento y archivo dictadas al amparo de lo previsto en el artículo 313 de la ley de Enjuiciamiento Criminal, deben considerarse injustas por contrarias a lo dispuesto en los artículos 7 y siguientes y al 318 de la ley Orgánica del Poder Judicial?, SÍ o NO.

Esos falsos demócratas, de uno u otro partido político que pronto comenzaran a solicitar nuestro voto -sabiéndose protegidos por el ejercicio corporativo- han demostrado que son capaces de transgredir el ordenamiento jurídico hasta el punto de infringir lo previsto en el artículo 542 del vigente Código Penal que dice: Incurrirá en la pena de inhabilitación especial para empleo o cargo público por tiempo de uno a cuatro años la autoridad o funcionario público que, a sabiendas, impida a una 
persona el ejercicio de otros derechos cívicos reconocidos por la Constitución y las leyes.

Con tan irregular postura demuestran los máximos representantes de la Soberanía Popular que desde sus asientos -casi siempre vacíos- la política del ladrillo y la ilusión de enriquecerse excesivamente les interesa más a nuestros representantes políticos que los fundamentales derechos de los ciudadanos, como demuestra el que no hayan actualizado la Ley de Enjuiciamiento Criminal, supuestamente para evitar que el ejercicio corporativo desaparezca y ellos, los políticos, puedan perder la impunidad de la que vienen gozando desde el año de gracia de 1882 en que dicha ley fue aprobada.

No haremos aquí referencia al constitucional derecho de los ciudadanos a participar en la Administración de Justicia mediante la institución del Jurado; de momento sépase que este constitucional derecho lo están vulnerando de forma intencionada los miembros del Congreso de los Diputados y del Senado que aprobaron las enmiendas presentadas por el Grupo Parlamentario Popular y Coalición Canaria al Proyecto de la Ley Orgánica del Tribunal del Jurado, supuestamente para evitar que aquellos funcionarios civiles del Estado incluidos magistrado jueces y miembros del Congreso y del Senado, sean juzgados por los miembros del Tribunal del Jurado y no mediante el ejercicio corporativo.

OTRO SÍ DICE EL ACTOR: No es de recibo que el Tribunal Constitucional no admita más que el $4 \%$ de los recursos de amparo que le presentan aquellas personas que sienten vulnerados sus derechos fundamentales en el largo calvario de la Administración de Justicia. Este hecho no hace sino confirmar que la justicia en España funciona excesivamente mal. Tampoco parece honesto que el Tribunal Constitucional de espaldas al constitucional derecho a la tutela judicial efectiva, que añade, sin que, en ningún caso, pueda producirse indefensión, acuerde in-admitir 
más del 96\% de los recursos de amparo que se le presentan cada año mediante simple Providencia, supuestamente obviando que ni la jurisprudencia es fuente del Derecho ni los autos integran la jurisprudencia.

Usted sabrá quiÉnes somos y lo que pretendemos si visita las Web:

http://www.derechos-fundamentales.com y http://www.CAyC.com.es, únase a nosotros, en sus manos está el conseguir para el pueblo soberano ejercer la potestad legislativa y controlar las acciones del Gobierno para que nuestros derechos cívicos sean respetados por los poderes del Estado. Joaquín González López DNI 173,785, en su propio nombre y derecho y en su calidad de Presidente de AJURA. www.ajura01@ajura.ong 